\title{
Strength Properties and Micro-structure of Steel Slag Based Hardened Cementitious Composite with Graphene Oxide
}

\author{
Mao $\mathrm{Li}^{1,}{ }^{,}$, Jin-man $\mathrm{Kim}^{2}$ \\ ${ }^{1}$ Ph.D student , Department of Architectural Engineering, 1223-24 Cheonan-daero, South Korea \\ ${ }^{2}$ Professor, Ph.D, Department of Architectural Engineering, 1223-24 Cheonan-daero, South Korea
}

\begin{abstract}
For the rapid hardening of concrete, various types of calcium aluminate composite have been used for special purpose as shotcrete or rapid repairing in construction field. However, high cost of calcium aluminates is demerit in the point of expanding usage. In recent years, a new binder for rapid hardening has been introduced as the pulverized ladle furnace slag (RC-LFS) with main components of $\mathrm{C}_{12} \mathrm{~A}_{7}$ and $\beta-\mathrm{C}_{2} \mathrm{~S}$. Like other traditional cementitious materials, it's use will preserve natural resources and has high environmental advantage with economic efficiency, by transferring the industry byproducts into high value materials. Even though flake state, graphene oxide has high tensile strength and electric conductivity. Then, it can be used to increase strength and thermal properties of concrete and its efficiency depends on the dispersion in the cement matrix. In this paper, we used graphene oxide for increasing the engineering properties in RC-LFS concrete with GGBFS. Test results showed that the $0.05 \mathrm{w} \%$ of graphene oxide increase the flexural strength to $26 \%$ and compressive strength to $16 \%$.
\end{abstract}

\section{INTRODUCTION}

Nowadays, many new materials with candidated reinforcing effect for cementitious composite are introduced. Though reinforcing mechanism and reinforcing efficiency are different on case by case, there are special attention to the graphene oxide (GO). GO is mono-layer of 2-hybridized carbon atoms derived from a mixture of carboxyl, hydroxyl, and epoxy functionalities $[1,2,3]$. It has been reported by Z. Pan and K. Gong et al. that carboxyl acid groups can react with calcium silicate hydrate (C-S-H) to form strong covalent bonds, thereby notably improving mechanical properties of GO-cement composites $[4,5]$.

For high aluminate composite, the properties of graphene oxide reinforced composite haven't been fully documented., This unconventional cementitious material, the binder in this experiment,also been introduced as the pulverized rapid cooling ladle furnace slag (RCLFS). Ladle furnace slag (LFS) is an industry by-product which generally occupied a large area of the land for store and processing. Thus it has generated a serious environmental

*Corresponding author: jmkim@kongjul.ac.kr 
problem for a long time. Moreover, the slow cooled LFS (by natural air) is hard for recycling, since the slowly cooled process allow the generation of crystal structure which lower the reactivity even after pulverized [6]. On the other hand, slow cooled also lead to high amount of $\mathrm{f}-\mathrm{CaO}$ which will cause the unsoundness problem [6, 7]. But after rapidly cooled by high-pressure air, the material shows remarkable mechanical properties and high early strength after pulverized. More importantly, many studies have been focusing on finding an alternative which can be used as cement replacement materials. Cement replacement materials are the way to utilized untouchable raw materials and should be a break-solution of a green world. Materials that can be used for replacing cement as a binder can come from several sources namely agriculture, industry, marines etc. [8]. The pulverized RC-LFS as an industry by-product has unique properties on reducing environmental problems and such a solution of sustainable development. Owing to its rapid strength development, pulverized RC-LFS was used in structural applications.

Except RC-LFS, ground granulated blast furnace slag (GGBFS) was also involved. GGBFS remains after the steel making process. Application of GGBFS in construction material development is not only cost effective and resource saving but also reduces the energy and green house gas emissions [9].

Since the necessity to document the mechanical properties such as flexural and compressive strength of GO reinforced mortar, those properties were evaluated by series experiment and were presented in this paper.

\section{EXPERIMENTAL STUDY}

\subsection{Materials}

Within the scope of this paper, four basic materials such as pulverized RC-LFS, $\alpha$ semihydrated gypsum, GGBFS, and GO are used. All those material are getting from Korea market.

The hydration of pulverized RC-LFS process very rapidly in the room temperature since the primary hydraulic material is $\mathrm{C}_{12} \mathrm{~A}_{7}$. Nowadays, gypsum always been involved in the pulverized RC-LFS based composite to hydrate with $\mathrm{C}_{12} \mathrm{~A}_{7}$ to form ettringite, thus to prevent from transforming from $\mathrm{C}_{2} \mathrm{AH}_{8}$ to $\mathrm{C}_{3} \mathrm{AH}_{6}$ as been illustrated in following equations [6].

$$
\begin{gathered}
\mathrm{C}_{12} \mathrm{~A}_{7}+51 \mathrm{H}_{2} \mathrm{O} \rightarrow 6 \mathrm{C}_{2} \mathrm{AH}_{8}+\mathrm{AH} \rightarrow 4 \mathrm{C}_{3} \mathrm{AH}_{6}+6 \mathrm{AH}+18 \mathrm{H}_{2} \mathrm{O} \\
\mathrm{C}_{12} \mathrm{~A}_{7}+12 \mathrm{CaSO}_{4}+137 \mathrm{H}_{2} \mathrm{O} \rightarrow 4\left(\mathrm{C}_{3} \mathrm{~A} \cdot 3 \mathrm{CaSO}_{4} \cdot 32 \mathrm{H}_{2} \mathrm{O}\right)+6 \mathrm{AH}
\end{gathered}
$$

While the hydration process of $\mathrm{C}_{12} \mathrm{~A}_{7}-\mathrm{CaSO}_{4} \cdot \mathrm{nH}_{2} \mathrm{O}$ system is very complicated. First of all, the amount of $\mathrm{CaSO}_{4} \cdot \mathrm{nH}_{2} \mathrm{O}$ has to be sufficient to guarantee the stable production of ettringite and can be calculated by using modified Bogue equation [6,7]. Base on the previous studies, chemical retarders are necessary to control the hydration process of C12A7. Since that, citrate acid was involved. GGBFS, as one of the most widely used supplementary cementitious material (SCM) in the construction field, has been documented by many researchers $[10,11$,$] . The addition of GGBFS to the calcium aluminate cement$ (CAC) system is reported to change the hydration mechanism of a CAC system. Previous studies have demonstrated that, in CAC-GGBFS blends of suitable ratios, no conversion even at elevated temperatures, even though various types of $\mathrm{CAC}$ with different alumina contents were utilized. $[12,13,14,15]$. The physical and chemical properties of pulverized RC-LFS, gypsum and GGBFS are presented in Table 1. 
GO used in this experiment was provided by a Korean Company. To guarantee the good distribution in the cementitious matrix, the aqueous solution was used as presented in Fig.1. The physical properties are shown in Table 2. The package which is provided by the company is $250 \mathrm{ml}$, and contents $0.75 \mathrm{~g}$ solid graphene oxide.

Table 1. The basic physical and chemical properties of LFS powder, gypsum, and GGBFS

\begin{tabular}{|c|c|c|c|c|c|c|c|c|}
\hline \multirow{2}{*}{ Binder } & \multicolumn{2}{|c|}{ Physical properties } & \multicolumn{6}{|c|}{ Oxide content(Wt.\%) } \\
\cline { 2 - 9 } & $\begin{array}{c}\text { Density } \\
\left(\mathrm{g} / \mathrm{cm}^{3}\right)\end{array}$ & $\begin{array}{c}\text { Fineness } \\
\left(\mathrm{g} / \mathrm{cm}^{3}\right)\end{array}$ & $\mathrm{SiO}_{2}$ & $\mathrm{CaO}$ & $\mathrm{Al}_{2} \mathrm{O}_{3}$ & $\mathrm{Fe}_{2} \mathrm{O}_{3}$ & $\mathrm{MgO}$ & $\mathrm{SO}_{3}$ \\
\hline RC-LFS & 2.97 & 6300 & 10.9 & 44.5 & 26.6 & 4.3 & 6.6 & - \\
\hline $\begin{array}{c}\text { Semi- } \\
\text { Gyp }\end{array}$ & 2.72 & 1100 & 2.6 & 40 & 0.9 & 0.4 & 0.3 & 55.8 \\
\hline GGBFS & 2.84 & 4200 & 30.3 & 44.6 & 13.8 & 0.5 & 4.5 & 4.4 \\
\hline
\end{tabular}

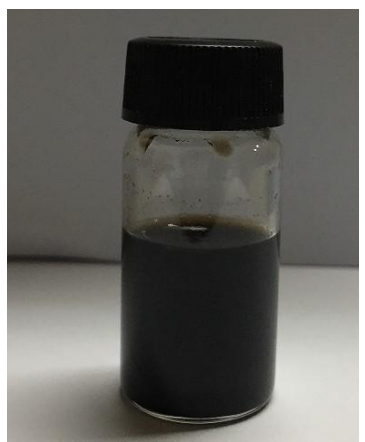

Fig. 1. Graphene oxide aqueous solution.

Table 2. Properties of solid graphene oxide

\begin{tabular}{|c|c|c|}
\hline Carbon (\%) & Oxygen (\%) & D/G ratio \\
\hline $45-50$ & $40-45$ & 0.99 \\
\hline
\end{tabular}

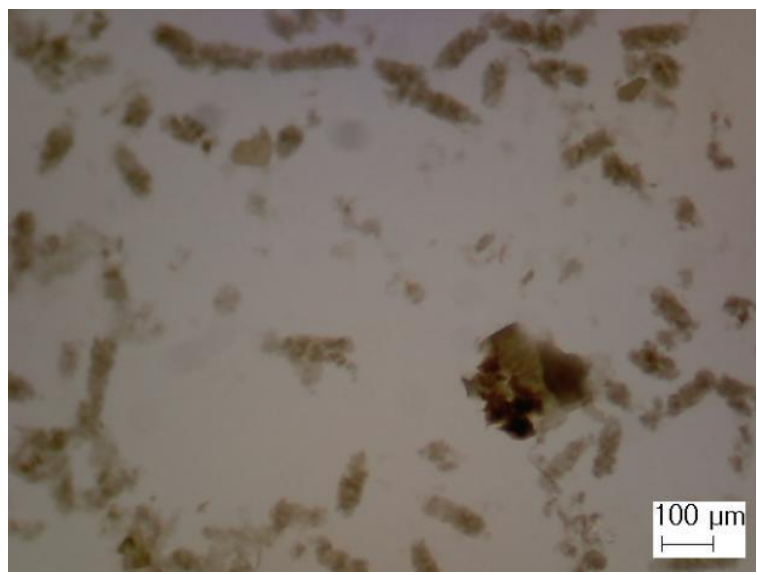

Fig. 2. Graphene oxide aqueous solution under the microscope. 


\subsection{Experimental plan}

The experimental purpose is to illustrate the micro-structure and strength development of RC-LFS base slag cement. Thus the experimental plan is decided and as presented in Table 3 . For the fresh composites, the test items include the flow and air content and will follow the ASTM C230 [16] and ASTM C185-08 [17] respectively. For hardened composite, flexural and compressive strength are involved by referencing ASTM C348-14 [18] and ASTM C349 [19].

The fresh concrete was cast in $40 * 40 * 160 \mathrm{~mm}$ prism mold. The curing room for storage

Table 3. Experimental plan

\begin{tabular}{|c|c|c|c|c|}
\hline Binder & ID & Dosage of GO & $\mathrm{w} / \mathrm{b}(\%)$ & Test items \\
\hline Ace*. $100 \%$ & A100 & \multirow{4}{*}{$\begin{array}{l}0.05 \\
\mathrm{w} \%\end{array}$} & \multirow{4}{*}{40} & \multirow{4}{*}{$\begin{array}{l}\text {-Flow } \\
\text {-Air content } \\
\text {-Flexural strength } \\
\text {-Compressive strength } \\
\text {-Microstructure (SEM) }\end{array}$} \\
\hline Ace*. $100 \%+\mathrm{GO}$ & A100GO & & & \\
\hline $\begin{array}{l}\text { Ace*.75\% } \\
+ \text { GGBFS }\end{array}$ & A75G25 & & & \\
\hline $\begin{array}{c}\text { Ace*.75\% } \\
+ \text { GGBFS }+ \text { GO }\end{array}$ & $\mathrm{A} 75 \mathrm{G} 25 \mathrm{GO}$ & & & \\
\hline \multicolumn{5}{|c|}{ Ace* : pulverized RC-LFS replaced by $25 \%$ of $\alpha$ semi-hydrate gypsum } \\
\hline
\end{tabular}

of the specimens in the mold is maintained at a temperature of $20.0 \pm 1.0^{\circ} \mathrm{C}$ and relative humidity of $60.0 \pm 5.0 \%$. The samples involved in this experiment can be differentiated by different binder material whether containing graphene oxide or not. The control mixtures identified as the mixture without graphene oxide and GGBFS. Other three mixtures contain GGBFS or/and graphene oxide. The different ingredient and ID has been shown in Table 3. The steps of preparing mixtures can be summarized as following:

1. Preparing and measuring binder material.

2. Measuring graphene oxide. The dosage was designed by the solid content of aqueous solution.

3. Modify and recalculate the water amount. Since the graphene oxide solution contains water, adding graphene oxide solution will improve the water-to-binder ratio. So the mixing water will be recalculated.

4. The temperature of all the material will be tested and well keeping in the curing room at $20^{\circ} \mathrm{C}$ and $60 \%$ relative humidity.

5. Mixing method will be based on the ASTM C305-06 [20]. Graphene oxide solution will be added into the mixtures after mixing water, and continued mixing for additional 1 minute at $285 \pm 10 \mathrm{r} / \mathrm{min}$.

\section{TEST RESULTS AND DISCUSSION}

\subsection{Flow, air content of fresh mixtures}

As a nanomaterial, GO was documented may have an influence on the fresh properties of the mixtures [21]. Since that, the fresh properties of graphene oxide have been tested by ASTM standard. Fresh cement material always illustrated as yield stress fluids [21,22], and the fresh properties of the mixtures have directly influence on the hardened composite. Thus, in this experiment, the air content and flow properties of GO composites have been evaluated. The experimental outcome is shown in Fig.3. The GO showed different effects on the different matrix. The tendency of air content and flow showed the similarity. First of all, GGBFS can increase the flow by thinning the RC-LFS. Secondly, the GO can decrease the flow when you compare the mixture A75G25 and A75G25GO. It is because of the large 
aspect ratio and nucleation effect $[1,23]$. While the increasing flow of the mixture A100GO is because the increasing the air content by the GO.

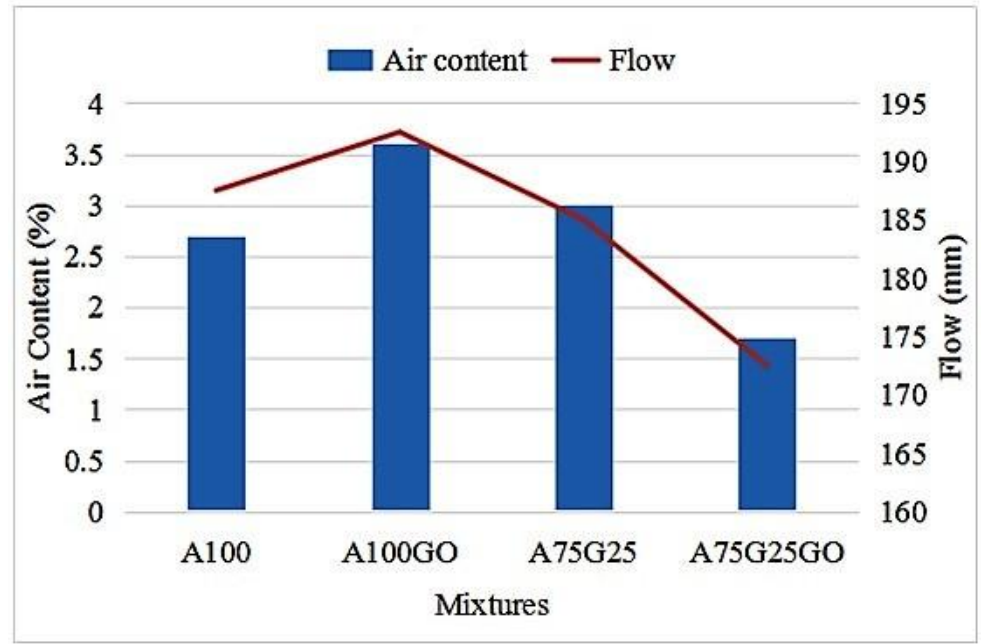

Fig. 3. Air content and flow of GO reinforced composite.

\subsection{Flexural, compressive strength and the microstructure}

Flexural and compressive strength will be tested after curing for 4 hours, 1 day, 7 days and 28 days. The test results as presented in Fig.4.First of all, the binder RC-LFS showed remarkable early strength. The four-hours compressive strength was over $30 \mathrm{MPa}$ of mixture A100 and A100GO. Even after replaced by $25 \mathrm{vl} \%$ of GGBFS, the four-hours strength still very closed to $30 \mathrm{MPa}$. After 28 days curing, the compressive of both A100 and A100GO were over $60 \mathrm{MPa}$. The flexural strength also showed high early strength of all four mixtures between 5 to $6 \mathrm{MPa}$. Secondly, the reinforcing effect of GO showed clearly. From the compare between those four mixtures, the max improvement of compressive strength was over $12 . \%$ and the max improvement of flexural strength was over $26 \%$.

The improvement can be summarized as four main reasons. First of all, the function group on the surface of graphene oxide provide high bonding strength between GO and hydrations (such as $\mathrm{C}-\mathrm{S}-\mathrm{H}$ and calcium hydroxide) of cement [1,2,23]. Secondly, as nanomaterial, GO can increase the load-transfer efficiency from cement matrix to the reinforcement [2]. Thirdly, nucleation effect can accelerate the hydration of cement matrix. Moreover, larger regular crystal hydration produce can be generated on the surface of GO and generally cover the GO with curing time. Thus, the concrete with GO shows relatively better engineering performance. Finally, it's also believed that GO nanosheet can provide the crack-bridging effect which has a positive effect on crack resistance [1,2,23]. Base on the previous researches, GO can provide both physical reinforcement and chemical reinforcement at the same time. 


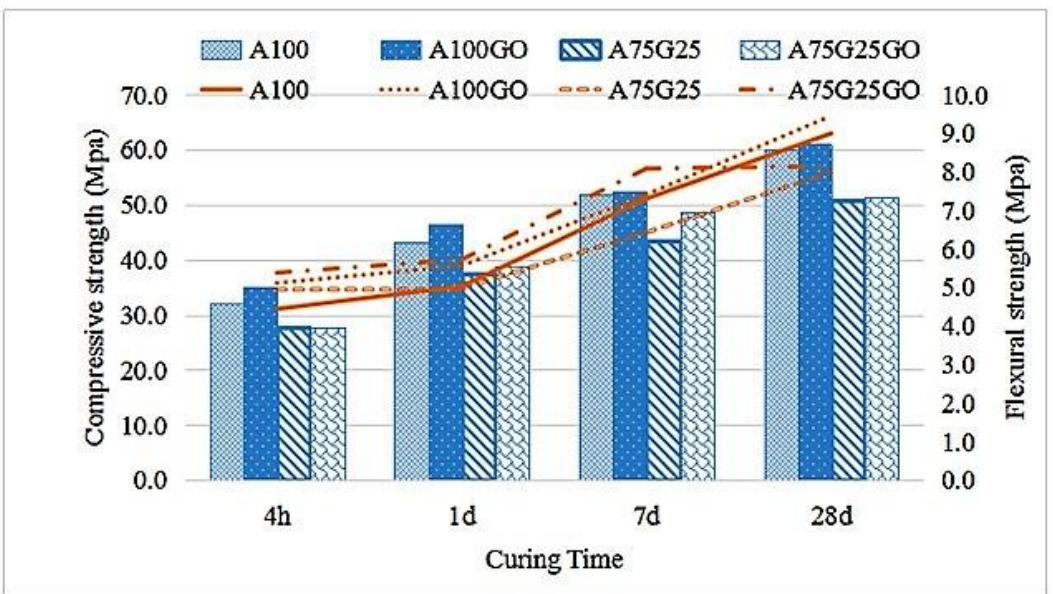

Fig. 4. Flexural and compressive strength.

In order to illustrate the mechanical properties, the microstructure of those mixtures also has been tested by SEM. The test result as shown in Fig.5.
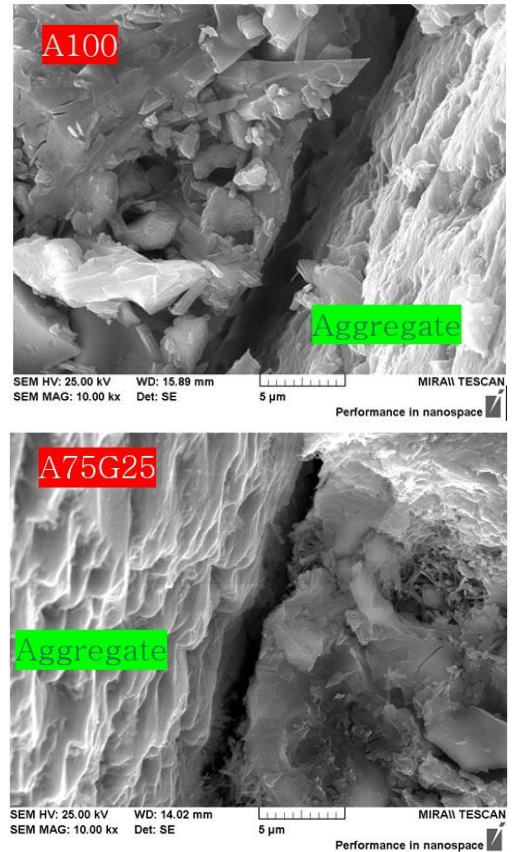
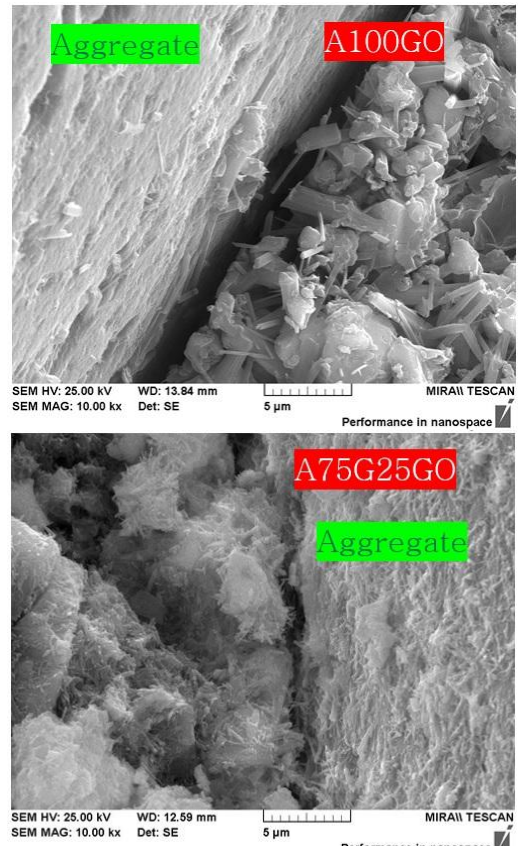

Fig. 5. The microstructure of hardened composite by SEM.

From the test results, the reinforcing effects of GO can also be noticed. The hydration product and the structures showed different. On the other hand, GO is very hard to be located in the matrix due to the nano size and also covered by the hydration productions.

\section{CONCLUSIONS}

This paper covers the experimental study about the engineering properties of graphene oxide slag based cementitious composites. The experimental outcomes indicate that 
graphene oxide can reinforce the hydraulic composite by both physical and chemical bounding. As nano sheet and 2D material with controllable functional groups, graphene oxide shows reinforcing effects. Only $0.05 \mathrm{w} \%$ by the weight of binder can increase the flexural strength up to $26 \%$ and flexural strength up to $12 \%$.

\section{References}

1. Wengui Li, Xiangyu Li, Shu Jian Chen, Yan Ming Liu, Wen Hui Duan, Surendra P. Shah, "Effects of graphene oxide on early-age hydration and electrical resistivity of Portland cement paste," Constr Build Mater, Volume 136, Pp. 506-514, (2017)

2. Y. Cao, J. Zhang, J. Feng, P. Wu, "Compatibilization of immiscible polymer blends using graphene oxide sheets," ACS Nano, 5 (7), pp. 5920 - 5927,(2011)

3. P.S. Avanish, M. Monika, C. Amita, S.K. Dhawan, "Graphene oxide/ ferrofluid/ cement composites for electromagnetic interference shielding application",

4. Z. Pan, L. He, L. Qiu, A.H. Korayem, G. Li, J.W. Zhu, F. Collins, D. Li, W.H. Duan, C. Wang, "Mechanical properties and microstructure of a graphene oxide-cement composite," Cement Concr. Compos, 58, pp. 140 - 147,(2015)

5. K. Gong, Z. Pan, A. Korayem, L. Qiu, D. Li, F. Collins, C. Wang, W.H. Duan, "Reinforcing effects of graphene oxide on Portland cement paste," J. Mater. Civ. Eng., 27 (2), p. A4014010,(2015)

6. Jin-Man Kim, Sun-Mi Choi, Dongyeop Han, "Improving the mechanical properties of rapid air cooled ladle furnace slag powder by gypsum," Constr. Build. Mater,127, pp. 93-101,(2016)

7. Sunmi Choi, Jin-Man Kim, Dongyeop Han, Ji-Ho Kim, "Hydration properties of ladle furnace slag powder rapid cooled by air," Constr. Build. Mater. 113,pp.682-690,(2016)

8. Evi Aprianti S, “A huge number of artificial waste material can be supplementary cementitious material (SCM) for concrete production - a review part II," Journal of Cleaner Production, Volume 142, Part 4, Pages 4178 - 4194,(2017)

9. D.D. Higgins, GGBS and sustainability, Proc. Inst. Civ. Eng. Constr. Mater, 160 (3), pp. 99 - 101,(2007), http://dx.doi.org/10.1680/coma. 2007.160.3.99

10. Mohamed Elchalakani, Tarek Aly, Emad Abu-Aisheh, "Sustainable concrete with high volume GGBFS to build Masdar City in the UAE," Case Studies in Construction Materials, Vol 1, Pages 10-24,(2014)

11. Önder Kırca, İ. Özgür Yaman, Mustafa Tokyay, Compressive strength development of calcium aluminate cement-GGBFS blends, Cement and Concrete Composites, Vol 35, Issue 1,, Pages 163-170, (2013)

12. K.C. Quillin, G. Osborne, A. Majumdar, B. Singh, "Effects of W/C ratio and curing conditions on Strength development in BRECEM concretes," Cem Concr Res, 31, pp. $627-632,(2001)$

13. A.J. Majumdar, B. Singh, "Properties of some blended high alumina cements," Cem Concr Res, 22, pp. 1101 - 1114,(1992)

14. K.C. Quillin, "Blended high alumina cements", Mater World, 1, pp. 103 - 105.(1993)

15. M. Heikal, M.S. Morsy, M.M. Radwan, "Electrical conductivity and phase composition of calcium aluminate cement containing air-cooled and water-cooled slag at 20, 40, and $60{ }^{\circ} \mathrm{C}$," Cem Concr Res, 35, pp. 1438-1446,(2005) 
16. ASTM, ASTM C230/C230M-14 Standard Specification for Flow Table for Use in Tests of Hydraulic Cement, ASTM Int. West Conshohocken

17. ASTM, ASTM C185 - 08 Standard Test Method for Air Content of Hydraulic Cement Mortar, ASTM Int. West Conshohocken

18. ASTM, ASTM C348-14 Standard Test Method for Flexural Strength of HydraulicCement Mortars, ASTM Int. West Conshohocken

19. ASTM, ASTM C349-14 Standard Test Method for Compressive Strength of Hydraulic-Cement Mortars (Using Portions of Prisms Broken in Flexure), ASTM Int. West Conshohocken

20. ASTM, ASTM C305 - 06 Standard Practice for Mechanical Mixing of Hydraulic Cement Pastes and Mortars of Plastic Consistency, ASTM Int. West Conshohocken

21. Qin Wang, Xinyou Cui, Jian Wang, Shiyu Li, Chunxiang Lv, Yichen Dong, "Effect of fly ash on rheological properties of graphene oxide cement paste", Constr. Build. Mater., Volume 138, Pages 35-44, (1 May 2017)

22. Konstantin Kovler, Nicolas Roussel, "Properties of fresh and hardened concrete", Constr. Build. Mater., Volume 41, Issue 7, Pages 775 - 792, (July 2011)

23. K.M. Liew, M.F. Kai, L.W. Zhang, "Carbon nanotube reinforced cementitious composites: An overview, Composites Part A: Applied Science and Manufacturing”, Volume 91, Part 1, Pages 301 - 323, ( December 2016) 